\title{
Human Microbiome in Children, at the Crossroad of Social Determinants of Health and Personalized Medicine
}

\author{
Talía Sainz ${ }^{1,2,3, *(\mathbb{D})}$, Valeria Pignataro ${ }^{4}$, Donato Bonifazi ${ }^{4,5}{ }^{\oplus}$, Simona Ravera ${ }^{6}$, María José Mellado ${ }^{1,2,3,5}{ }^{\circ}$, \\ Antonio Pérez-Martínez 1,2,7 (D) Adela Escudero ${ }^{1,2}{ }^{(D}$, Adriana Ceci ${ }^{4,5}$ and Cristina Calvo ${ }^{1,2,3,7}$ (D) \\ 1 Hospital La Paz, Po Castellana 261, 28046 Madrid, Spain; mariajose.mellado@salud.madrid.org (M.J.M.); \\ aperezmartinez@salud.madrid.org (A.P.-M.); adela.escudero@salud.madrid.org (A.E.); \\ ccalvorey@gmail.com (C.C.) \\ 2 La Paz Hospital Reserach Institute (IdiPAZ), P Castellana 261, 28046 Madrid, Spain \\ 3 CIBER de Enfermedades Infecciosas (CIBERInfec), Instituto de Salud Carlos III (ISCIII), 28029 Madrid, Spain \\ 4 Consorzio per Valutazioni Biologiche e Farmacologiche, Via N. Putignani n. 178, 70122 Bari, Italy; \\ vpignataro92@gmail.com (V.P.); dbonifazi@cvbf.net (D.B.); AdriCeci.uni@Gmail.com (A.C.) \\ 5 TEDDY European Network of Excellence for Paediatric Research, Via Luigi Porta 14, 27100 Pavia, Italy \\ 6 PHArmaceutical Research Management SRL, Via Albert Einstein, 26900 Lodi, Italy; sravera@cvbf.net \\ 7 Departamento de Pediatría, Universidad Autónoma de Madrid (UAM), 28049 Madrid, Spain \\ * Correspondence: tsainzcosta@gmail.com or talia.sainz@salud.madrid.org
}

check for updates

Citation: Sainz, T.; Pignataro, V.; Bonifazi, D.; Ravera, S.; Mellado, M.J.; Pérez-Martínez, A.; Escudero, A.; Ceci, A.; Calvo, C. Human Microbiome in Children, at the Crossroad of Social Determinants of Health and Personalized Medicine. Children 2021, 8, 1191. https:// doi.org/10.3390/children8121191

Received: 25 October 2021

Accepted: 8 December 2021

Published: 16 December 2021

Publisher's Note: MDPI stays neutral with regard to jurisdictional claims in published maps and institutional affiliations.

Copyright: (c) 2021 by the authors. Licensee MDPI, Basel, Switzerland. This article is an open access article distributed under the terms and conditions of the Creative Commons Attribution (CC BY) license (https:/ / creativecommons.org/licenses/by/ $4.0 /)$.

\begin{abstract}
The evolving field of microbiome research offers an excellent opportunity for biomarker identification, understanding drug metabolization disparities, and improving personalized medicine. However, the complexities of host-microbe ecological interactions hinder clinical transferability. Among other factors, the microbiome is deeply influenced by age and social determinants of health, including environmental factors such as diet and lifestyle conditions. In this article, the bidirectionality of social and host-microorganism interactions in health will be discussed. While the field of microbiome-related personalized medicine evolves, it is clear that social determinants of health should be mitigated. Furthermore, microbiome research exemplifies the need for specific pediatric investigation plans to improve children's health.
\end{abstract}

Keywords: child; social determinants of health; human microbiome; personalized medicine

\section{Introduction}

The evolving field of the microbiome has revolutionized biomedical research in recent years, where it has emerged as an independent research specialty. In medicine, applied microbiome research offers new opportunities, including biomarker discovery, development of therapeutic targets, understanding of disparities in drug metabolization, and avenues for personalized medicine [1]. However, the complexities of the host-microbe ecological interactions hinder clinical transferability.

Personalized medicine (PM), also called precision or individualized medicine, is a promising field that may help clinicians determine which medical treatments will work best for each patient [2]. The simplest definition would be "the provision of the right treatment to the right patient at the right dose at the right time" [3]. As not all patients respond in the same way to a given therapy, PM has the potential to make medical practice more efficient based on genetic, biological, or psychosocial characteristics [4-6]. All these factors are to be taken into account for medical management, together with patient preferences.

Research in pharmacogenomics, proteomics, and metabolomics has already led to the identification of several genes, mRNA, proteins, and metabolites that can act as biomarkers and reliably reflect inter-individual variability in disease expression, with the potential to predict outcomes. Different biomarkers are being tested in experimental studies, but only a few have been already integrated into clinical practice [7]. Today, the microbiome is envisioned as one of the most critical and hypothetically modifiable markers of disease [1]. 
While the evidence supporting the interaction between the human host and the microbiome increases, the identification of microbiome-related biomarkers and the understanding of the role of microbiota in drug metabolization are also the focus of intense research. However, whether genetic or related to microbiota, validation of biomarkers among adults does not necessarily imply its usefulness in children, as gene expression and microbial colonization vary during childhood. It is known that the microbiome is established mainly during the first year of life, although fluctuations in the ecosystem occur over time together with lifetime changes [8]. Beyond age and genetic factors, the microbiome is deeply influenced by geographical, dietary, and lifestyle-related factors [9]. Studies suggest that these factors may be especially relevant in shaping the microbiome during childhood $[7,8]$. Social determinants of health have a direct impact on undoubtfully critical factors for health, such as malnutrition, access to treated water, or health care. In comparison, their effect on microbiota composition and how much these changes may contribute to health and disease may seem trivial and has not been well established.

\section{Social Determinants of Health and the Microbiome in Children}

Social inequities, poverty, or racism have profound impacts on life expectancy [3]. Defined by the World Health Organization as the "conditions in which people are born, grow, work, live, and age and the wide set of forces and systems shaping the conditions of daily life" [10], the so-called social determinants of health (SDOH) are known to have a powerful effect on health outcome [11-13]. Disparities among children's health and healthcare utilization along demographic lines such as race and income have long been documented as factors influencing children's morbidity and mortality [10]. Although SDOH influence health and well-being across individuals of all ages, in children and young people, physical, social, and emotional capabilities that develop early in life provide the basis for life course health and well-being [14]. Emerging data demonstrate that exposure to violence, food scarcity, poverty, and lack of housing, as well as race, ethnicity, gender, education, and health literacy, are potent determinants and comorbid issues for many conditions [13]. Recently, the human microbiome has been identified as a potentially modifiable determinant of health, which is highly determined itself by social and geographical conditions.

Although our understanding of the impact of the human microbiome on health is still in the early stages, current knowledge indicates that the interaction between microbiota and the host is strong. Around $10^{13}$ microorganisms, including bacteria, viruses, fungi, and protozoa, accounting for a total mass of $0.2 \mathrm{~kg}$ [15], inhabit our bodies and constitute the human microbiome. An overwhelming amount of data has underlined the influence of the first years of life to shape the microbiome-immune system interactions in recent years. Very early in life, the microbiome is first established by the colonization of microorganisms from the mother's skin, genital tract microbiota, breast milk, and after the introduction of complementary feeding $[16,17]$. Factors related to the mode of delivery, antimicrobial exposure early in life, or breast-feeding duration have been shown to impact microbiota acquisition $[8,16]$. Furthermore, it is known that these factors condition variations in gut microbiota that are associated with an increased risk of suffering from allergic diseases, asthma, celiac disease, or inflammatory bowel disease $[17,18]$. Geographic location and ethnicity also determine variability in the ecosystem [19], together with well-known dietary and lifestyle-related factors [17].

These environmental factors are deeply related to socio-economic conditions, including dietary restrictions, hygiene habits, housing conditions, and access to treated water or health care. Dietary habit modifications in the course of migration, for example, are key in shaping the gut microbiota. An ecosystem enriched in microorganisms specialized in degrading fibers, characteristic of children living in limited-resource settings, can be an adaptation to enhance energy obtention from the diet but could turn deleterious in the presence of a westernized diet [20].

The geographical variability of vaccine response is another compelling example of the critical implications of host-microbiome and environmental interactions [21]. In low- 
income countries, the poorer immunization rates achieved by oral vaccines (cholera, poliovirus, and rotavirus) have been classically related to environmental, socio-economic, or nutritional conditions [22]. However, it may also be explained by changes in the intestinal microbiota composition [21]. In a kind of infinite loop, dietary factors have a clear impact on the microbiome. Still, changes in the microbiome can lead to behavioral adaptations, leading to a subsequent modification in dietary habits [23]. Among other challenges in the field, causality is always questionable in most microbiome studies in humans. Autism spectrum disorder (ASD), common comorbidities of which are functional gastrointestinal disorders [24], is an excellent example of this bidirectionality. Manipulation of the gut microbiome could offer a promising treatment option for children with ASD. Recently, significant changes in serum neurotransmitters and an improvement in behavioral and gastrointestinal symptoms were observed during a fecal microbiota transplantation trial in children diagnosed with autism [25]. Yet, the longitudinal follow-up would be essential for further understanding of the so-called "gut-brain" axis.

The fact that the gut microbiome in children living in resource-limited settings has remained underreported in microbiome research is another clear example of how social inequities impact health from the very primary step of knowledge generation. Nevertheless, consistent data illustrate how pathogenic species are often detected in higher abundance among malnourished children living in low-income settings $[19,26]$. While there is agreement that nutrition and gut microbiota are linked, particularly in vulnerable populations such as children, it is highly controversial to what extent the theoretically modifiable human microbiome is a potential therapeutic target. Fecal microbiota transplantation has shown efficacy in very limited settings (recurrent Clostridioides difficile associated diarrhea). Still, studies addressing the role of microbiota modulation with probiotics, prebiotics, or dietary interventions in treating and recovering from infections or inflammatory diseases have raised controversial results [27-29]. Although these treatments' impact and therapeutic potential have not been well-established yet, the evidence supports the need to implement measures to prioritize food security worldwide. Making nutritional modifications in areas with limited resources is a challenge, but it is also a priority to improve health.

Untangling the crossroad of SDOH, the human microbiome, and human health is a formidable challenge (Figure 1). Unfortunately, because the individual's microbiota is fundamentally established during the first three years of life (from childbirth to the consolidation of the adult diet) [17], the impact of socio-economic factors on the microbiome composition might be more significant in children compared to adults. An "unfavorable" microbiota may cause lasting damage $[20,30]$. Hence, the idea of the bidirectionality of social and host-microorganism interactions in health should be integrated into research and clinical perspectives from today. In addition to the possible therapeutic implications, some of them already mentioned, modification of the microbiota in childhood has been postulated to be key in the prevention of infections [31], allergy [32], asthma [33], or even cancer in childhood [34-36]. Therefore, the inclusion of children in clinical trials evaluating dietary modifications and their impact on various diseases and overall health should be prioritized. 


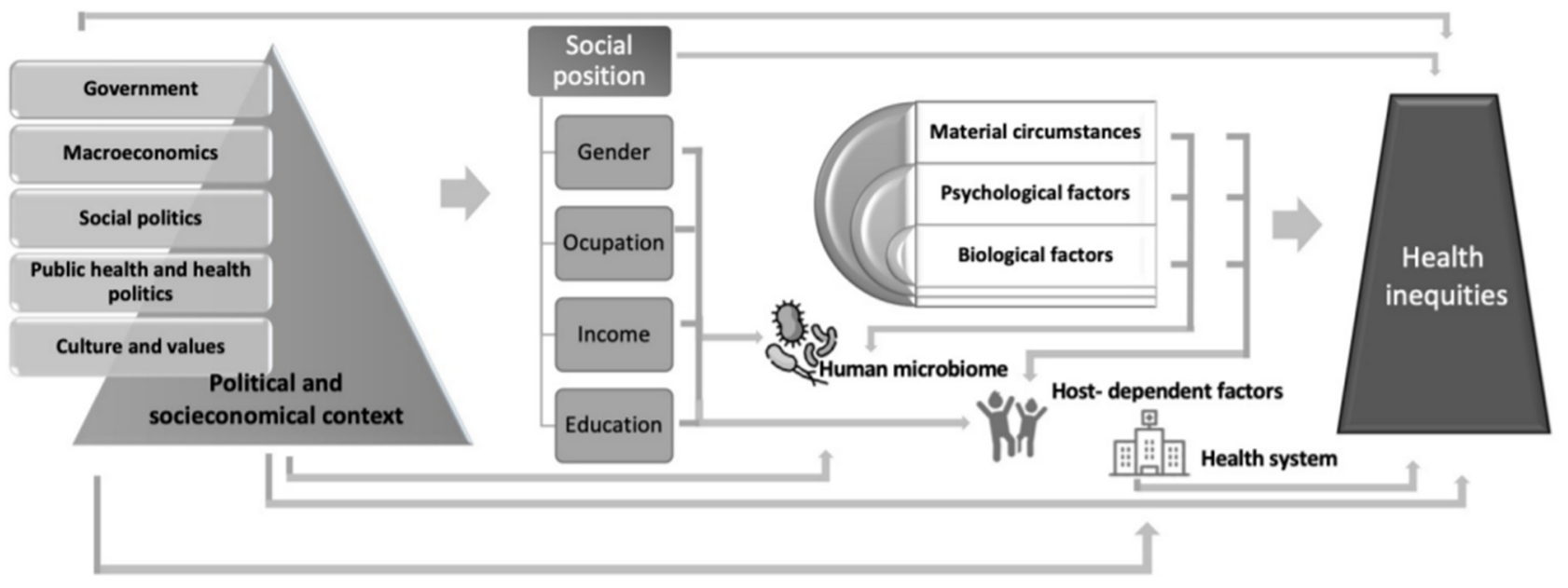

Figure 1. Human microbiome at the crossroad between social determinants of health and personalized medicine.

\section{Personalized Medicine and the Microbiome}

Therapeutic efforts to target the microbiome have shown, as mentioned, contradictory results [37-39]. Modulation of the microbiota with probiotics, prebiotics, dietary interventions, or even fecal microbiota transplantation is under research. However, apart from the treatment of Clostridioides difficile-associated diarrhea, there have been few impacts in terms of clinical practice outside research. Beyond the hospital environment, nevertheless, diet is increasingly appreciated to have a tremendous impact on many aspects of life, including health and disease. Personalized nutrition aims to characterize inter-individual host and microbiome variations and generate data-driven personalized dietary recommendations [40] and is becoming more and more popular worldwide. The concept would be as follows: first, the diet gives rise to a specific microbiota for each person. Second, characterization of the individual's microbiome and gut-derived metabolites would be directed towards a personalized nutrition plan.

This holistic approach does not seem feasible for disease treatment, where personalized medicine requires the identification of key proteomic, metabolomic, or microbiomerelated biomarkers. In fact, the search for biomarkers that allow anticipating and monitoring disease has been a constant in medical research. The potential applications of microbiota-related biomarkers and metabolic/immune check-points in all areas of medicine, from obesity to cancer, are endless. Most attempts to personalize the approach based on microbiome contributions to human health come from research in diabetes [41], cardiovascular disease [42], metabolic syndrome/obesity [43], and cancer [44]. Short-chain fatty acids (SCFAs) such as butyrate, acetate, or propionate [45] are critical drivers of T-cell subset proliferation and activity [46], and they are produced after fermentation of complex dietary carbohydrates by gastrointestinal bacteria. These metabolites have been suggested to influence both maternal and newborn down-regulation of pro-inflammatory responses, playing an essential role in tolerance phenomena and atopy and asthma in childhood [47].

The diagnostic and therapeutic potential of SCAs is being explored in different settings, from allergies to autoimmune disorders such as systemic lupus erythematosus [48]. In addition, SCFAs and other microbiota-derived metabolites such as lipopolysaccharides, beta-cresol, and bacterial toxins in blood and urine are being explored as diagnostic tools and for early intervention in autism spectrum disorder [49]. In this context, despite the uncertainty regarding the cause-to-effect relationship, the diagnostic potential is appealing, and the design of personalized treatments seems promising. The tumor microenvironment is another focus of intense research nowadays. In colorectal cancer, gut microbiota biomarkers have gained attention for their potential for early non-invasive diagnosis, with good 
sensitivity, specificity, and even cost-effectiveness [50]. A similar approach has been made in esophageal cancer [51], and clinical trials are ongoing for fecal microbiota transplantation as an immunomodulatory strategy to improve response to treatment among advanced lung cancer patients [52].

The future clinical relevance of the microbiome and microbiota-derived compounds as new biomarkers for diagnosis and targeted interventions in medicine is unclear. Still, it represents an important proportion of options being explored today for personalized medicine. Unfortunately, most of these investigations will not be transferable to children, as the evolving nature of the microbiome impairs us from extrapolating adults' data. To bring the promise of personalized medicine to children, specific pediatric investigation plans that contemplate the design of studies aimed at typical childhood pathologies and the inclusion of children in clinical trials are required. Plasticity might be more remarkable in children in terms of targeting the microbiome, and achieving long-lasting effects might be easier in a non-established ecosystem, making it even more important to prioritize pediatric investigation in the field. Longitudinal studies, together with new tools for a functional approach to the microbiome and an ecological perspective, are required to deepen our understanding of such a complex field.

\section{Conclusions}

To what extent the study of the microbiome will have clinical implications is still an unanswered question, but promising research points towards the development of a microbiome-based personalized medicine. Microbiome composition is deeply influenced by socio-economic factors, especially during childhood. While the field of microbiomerelated personalized medicine evolves, it is clear that $\mathrm{SDOH}$ can and should be mitigated. Improving living conditions and fighting the unequal distribution of power, money, and resources is crucial for children. Due to the evolving nature of the microbiome, children will need to be the focus of research if the aim is to bring personalized medicine to pediatrics.

Author Contributions: Conceptualization, T.S.; C.C.; M.J.M.; D.B.; V.P.; A.P.-M. methodology, T.S.; C.C.; M.J.M.; D.B.; V.P.; A.P.-M.; S.R.; A.E.; A.C.; investigation, C.C.; M.J.M.; D.B.; V.P.; S.R.; A.P.-M.; A.E.; A.C.; writing-original draft preparation, T.S.; C.C.; D.B.; V.P.; A.E.; S.R.; writing-review and editing, T.S.; C.C.; M.J.M.; D.B.; V.P.; A.P.-M.; A.E.; S.R.; A.C.; project administration, D.B., V.P., A.C.; funding acquisition, D.B.; M.J.M.; V.P.; A.C. All authors have read and agreed to the published version of the manuscript.

Funding: The research was funded by European Paediatric Translational Research Infrastructure (designed under European Union-Horizon 2020: GA 777554). Talía Sainz has been funded by a Grant from the Spanish Society of Infectious Diseases (SEIMC).

Institutional Review Board Statement: Not applicable.

Informed Consent Statement: Not applicable.

Data Availability Statement: Not applicable.

Conflicts of Interest: The authors declare that they have no conflict of interest.

\section{References}

1. Yao, Y.; Cai, X.; Ye, Y.; Wang, F.; Chen, F.; Zheng, C. The Role of Microbiota in Infant Health: From Early Life to Adulthood. Front. Immunol. 2021, 12, 4114. [CrossRef]

2. Personalized Medicine Coalition. The Case for Personalized Medicine 3rd ed. Available online: http://www.personalizedmedici necoalition.org/ (accessed on 20 August 2012).

3. European Commission-Pharmaceutical Committee. Report on the Use of -Omic Technologies in the Development of Personalised Medicine. Available online: https:/ /www.europarl.europa.eu/RegData/etudes/BRIE/2015/569009/EPRS_BRI(2015)569009_ EN.pdf (accessed on 27 October 2015).

4. Ramaswami, R.; Bayer, R.; Galea, S. Precision Medicine from a Public Health Perspective. Annu. Rev. Public Health 2018, 39, 153-168. [CrossRef]

5. Yousif, T.I.; Bizanti, K.; Elnazir, B. Uses of Personalised Medicine in Current Pediatrics. Int. J. Clin. Pediatr. 2016, 5, 1-5. [CrossRef] 
6. Iriart, J.A.B. Precision medicine/personalized medicine: A critical analysis of movements in the transformation of biomedicine in the early 21st century. Cad. Saude Publica 2019, 35, e00153118. [CrossRef]

7. Taylor, M.; Allada, V.; Moritz, M.L.; Nowalk, A.J.; Sindhi, R.; Aneja, R.K.; Torok, K.; Morowitz, M.J.; Michaels, M.; Carcillo, J.A. Use of C-Reactive Protein and Ferritin Biomarkers in Daily Pediatric Practice. Pediatr. Rev. 2020, 41, 172-183. [CrossRef] [PubMed]

8. Mesa, M.D.; Loureiro, B.; Iglesia, I.; Gonzalez, S.F.; Olivé, E.L.; Algar, O.G.; Solana, M.J.; Perez, M.J.C.; Sainz, T.; Martinez, L.; et al. The Evolving Microbiome from Pregnancy to Early Infancy: A Comprehensive Review. Nutrients 2020, 12, 133. [CrossRef]

9. Gantenbein, K.; Kanaka-Gantenbein, C. Mediterranean Diet as an Antioxidant: The Impact on Metabolic Health and Overall Wellbeing. Nutrients 2021, 13, 1951. [CrossRef] [PubMed]

10. World Health Organization. Social Determinants of Health [Internet]. Available online: https://www.who.int/social_determina nts/en/ (accessed on 30 January 2020).

11. Narayan, A.; Raphael, J.; Rattler, T.; Bocchini, C. Social Determinants of Health-Screening in the Clinical Setting. Available online: https:/ / www.texaschildrens.org/ (accessed on 13 October 2021).

12. Braveman, P.; Egerter, S.; Williams, D.R. The Social Determinants of Health: Coming of Age. Annu. Rev. Public Health 2011, 32, 381-398. [CrossRef] [PubMed]

13. Jemal, A.; Thun, M.J.; Ward, E.E.; Henley, S.J.; Cokkinides, V.E.; Murray, T.E. Mortality from Leading Causes by Education and Race in the United States. Am.J. Prev. Med. 2008, 34, 1-8.e7. [CrossRef] [PubMed]

14. Sokol, R.; Austin, A.; Chandler, C.; Byrum, E.; Bousquette, J.; Lancaster, C.; Doss, G.; Dotson, A.; Urbaeva, V.; Singichetti, B.; et al. Screening Children for Social Determinants of Health: A Systematic Review. Pediatrics 2019, 144, e20191622. [CrossRef]

15. Sender, R.; Fuchs, S.; Milo, R. Revised Estimates for the Number of Human and Bacteria Cells in the Body. PLoS Biol. 2016, 14, e1002533. [CrossRef] [PubMed]

16. Shao, Y.; Forster, S.C.; Tsaliki, E.; Vervier, K.; Strang, A.; Simpson, N.; Kumar, N.; Stares, M.D.; Rodger, A.; Brocklehurst, P.; et al. Stunted microbiota and opportunistic pathogen colonization in caesarean-section birth. Nature 2019, 574, 117-121. [CrossRef] [PubMed]

17. Moore, R.E.; Townsend, S.D. Temporal development of the infant gut microbiome. Open Biol. 2019, 9, 190128. [CrossRef]

18. Fujimura, K.E.; Sitarik, A.R.; Havstad, S.; Lin, D.L.; LeVan, S.; Fadrosh, D.; Panzer, A.R.; LaMere, B.; Rackaityte, E.; Lukacs, N.W.; et al. Neonatal gut microbiota associates with childhood multisensitized atopy and T cell differentiation. Nat. Med. 2016, 22, 1187-1191. [CrossRef] [PubMed]

19. Gaulke, C.A.; Sharpton, T.J. The influence of ethnicity and geography on human gut microbiome composition. Nat. Med. 2018, 24, 1495-1496. [CrossRef]

20. De Filippo, C.; Di Paola, M.; Ramazzotti, M.; Albanese, D.; Pieraccini, G.; Banci, E.; Miglietta, F.; Cavalieri, D.; Lionetti, P. Diet, environments, and gut microbiota. A preliminary investigation in children living in rural and urban burkina faso and italy. Front. Microbiol. 2017, 8, 1979. [CrossRef]

21. Ciabattini, A.; Olivieri, R.; Lazzeri, E.; Medaglini, D. Role of the Microbiota in the Modulation of Vaccine Immune Responses. Front. Microbiol. 2019, 10, 1305. [CrossRef]

22. Zimmermann, P.; Curtis, N. The influence of the intestinal microbiome on vaccine responses. Vaccine 2018, 36, 4433-4439. [CrossRef] [PubMed]

23. Loughman, A.; Ponsonby, A.-L.; O’Hely, M.; Symeonides, C.; Collier, F.; Tang, M.L.; Carlin, J.; Ranganathan, S.; Allen, K.; Pezic, A.; et al. Gut microbiota composition during infancy and subsequent behavioural outcomes. EBioMedicine 2020, 52, 102640. [CrossRef]

24. Mitchell, L.K.; Davies, P.S.W. Pre- and probiotics in the management of children with autism and gut issues: A review of the current evidence. Eur. J. Clin. Nutr. 2021, 1-9. [CrossRef] [PubMed]

25. Li, N.; Chen, H.; Cheng, Y.; Xu, F.; Ruan, G.; Ying, S.; Tang, W.; Chen, L.; Chen, M.; Lv, L.; et al. Fecal Microbiota Transplantation Relieves Gastrointestinal and Autism Symptoms by Improving the Gut Microbiota in an Open-Label Study. Front. Cell. Infect. Microbiol. 2021, 11, 948. [CrossRef]

26. Huey, S.L.; Jiang, L.; Fedarko, M.W.; McDonald, D.; Martino, C.; Ali, F.; Russell, D.G.; Udipi, S.A.; Thorat, A.; Thakker, V.; et al. Nutrition and the Gut Microbiota in 10- to 18-Month-Old Children Living in Urban Slums of Mumbai, India. mSphere 2020, 5, e00731-20. [CrossRef]

27. Serrano-Villar, S.; De Lagarde, M.; Castellanos, J.F.V.; Vallejo, A.; Bernadino, J.I.; Madrid, N.; Matarranz, M.; Díaz-Santiago, A.; Gutierrez, C.; Cabello, A.; et al. Effects of Immunonutrition in Advanced Human Immunodeficiency Virus Disease: A Randomized Placebo-controlled Clinical Trial (Promaltia Study). Clin. Infect. Dis. 2018, 68, 120-130. [CrossRef]

28. Khanna, S.; Raffals, L.E. The Microbiome in Crohn's Disease. Gastroenterol. Clin. N. Am. 2017, 46, 481-492. [CrossRef]

29. Solomon, I.; Ilie, M.A.; Draghici, C.; Voiculescu, V.M.; Căruntu, C.; Boda, D.; Zurac, S. The impact of lifestyle factors on evolution of atopic dermatitis: An alternative approach (Review). Exp. Ther. Med. 2018, 17, 1078-1084. [CrossRef] [PubMed]

30. Burcham, Z.M.; Scientists, G.O.T.L.C.; Garneau, N.; Comstock, S.S.; Tucker, R.M.; Knight, R.; Metcalf, J.L. Patterns of Oral Microbiota Diversity in Adults and Children: A Crowdsourced Population Study. Sci. Rep. 2020, 10, 2133. [CrossRef]

31. Schwenger, E.M.; Tejani, A.M.; Loewen, P. Probiotics for preventing urinary tract infections in adults and children. Cochrane Database Syst. Rev. 2015, 12, CD008772. [CrossRef] [PubMed] 
32. De Filippis, F.; Paparo, L.; Nocerino, R.; Della Gatta, G.; Carucci, L.; Russo, R.; Pasolli, E.; Ercolini, D.; Berni Canani, R. Specific gut microbiome signatures and the associated pro-inflammatory functions are linked to pediatric allergy and acquisition of immune tolerance. Nat. Commun. 2021, 12, 5958. [CrossRef]

33. Lopez-Santamarina, A.; Gonzalez, E.; Lamas, A.; Mondragon, A.; Regal, P.; Miranda, J. Probiotics as a Possible Strategy for the Prevention and Treatment of Allergies. A Narrative Review. Foods 2021, 10, 701. [CrossRef]

34. Harrison, C.J. Prevention of childhood leukaemia by lifestyle changes. Leukemia 2021, 35, 1265-1266. [CrossRef]

35. Masetti, R.; Muratore, E.; Leardini, D.; Zama, D.; Turroni, S.; Brigidi, P.; Esposito, S.; Pession, A. Gut microbiome in pediatric acute leukemia: From predisposition to cure. Blood Adv. 2021, 5, 4619-4629. [CrossRef]

36. Greaves, M.; Cazzaniga, V.; Ford, A. Can we prevent childhood Leukaemia? Leukemia 2021, 35, 1258-1264. [CrossRef] [PubMed]

37. Gupta, A.; Khanna, S. Fecal Microbiota Transplantation. JAMA 2017, 318, 102. [CrossRef] [PubMed]

38. Freedman, S.B.; Williamson-Urquhart, S.; Farion, K.J.; Gouin, S.; Willan, A.R.; Poonai, N.; Hurley, K.; Sherman, P.M.; Finkelstein, Y.; Lee, B.E.; et al. Multicenter Trial of a Combination Probiotic for Children with Gastroenteritis. N. Engl. J. Med. 2018, 379, 2015-2026. [CrossRef]

39. Sainz, T.; Gosalbes, M.J.; Talavera-Rodríguez, A.; Jimenez-Hernandez, N.; Prieto, L.; Escosa, L.; Guillén, S.; Ramos, J.T.; MuñozFernández, M.Á.; Moya, A.; et al. Effect of a Nutritional Intervention on the Intestinal Microbiota of Vertically HIV-Infected Children: The Pediabiota Study. Nutrients 2020, 12, 2112. [CrossRef] [PubMed]

40. Kviatcovsky, D.; Zheng, D.; Elinav, E. Gut microbiome and its potential link to personalized nutrition. Curr. Opin. Physiol. 2021, 22, 100439. [CrossRef]

41. Zhao, L.; Zhang, F.; Ding, X.; Wu, G.; Lam, Y.Y.; Wang, X.; Fu, H.; Xue, X.; Lu, C.; Ma, J.; et al. Gut bacteria selectively promoted by dietary fibers alleviate type 2 diabetes. Science 2018, 359, 1151-1156. [CrossRef]

42. Wan, Y.; Wang, F.; Yuan, J.; Li, J.; Jiang, D.; Zhang, J.; Li, H.; Wang, R.; Tang, J.; Huang, T.; et al. Effects of dietary fat on gut microbiota and faecal metabolites, and their relationship with cardiometabolic risk factors: A 6-month randomised controlled-feeding trial. Gut 2019, 68, 1417-1429. [CrossRef] [PubMed]

43. San-Cristobal, R.; Navas-Carretero, S.; Martínez-González, M.Á.; Ordovas, J.M.; Martínez, J.A. Contribution of macronutrients to obesity: Implications for precision nutrition. Nat. Rev. Endocrinol. 2020, 16, 305-320. [CrossRef]

44. Janney, A.; Powrie, F.; Mann, E.H. Host-microbiota maladaptation in colorectal cancer. Nat. Cell Biol. 2020, 585, 509-517. [CrossRef]

45. Smith, P.M.; Howitt, M.R.; Panikov, N.; Michaud, M.; Gallini, C.A.; Bohlooly, Y.M.; Glickman, J.N.; Garrett, W.S. The microbial metabolites, short-chain fatty acids, regulate colonic Treg cell homeostasis. Science 2013, 341, 569-573. [CrossRef] [PubMed]

46. Furusawa, Y.; Obata, Y.; Hase, K. Commensal microbiota regulates T cell fate decision in the gut. Semin. Immunopathol. 2014, 37, 17-25. [CrossRef] [PubMed]

47. Havstad, S.; Johnson, C.C.; Kim, H.; Levin, A.M.; Zoratti, E.M.; Joseph, C.L.; Ownby, D.R.; Wegienka, G. Atopic phenotypes identified with latent class analyses at age 2 years. J. Allergy Clin. Immunol. 2014, 134, 722-727.e2. [CrossRef]

48. Zhang, L.; Qing, P.; Yang, H.; Wu, Y.; Liu, Y.; Luo, Y. Gut Microbiome and Metabolites in Systemic Lupus Erythematosus: Link, Mechanisms and Intervention. Front. Immunol. 2021, 12, 2678. [CrossRef]

49. Al-Ayadhi, L.; Zayed, N.; Bhat, R.S.; Moubayed, N.M.S.; Al-Muammar, M.N.; El-Ansary, A. The use of biomarkers associated with leaky gut as a diagnostic tool for early intervention in autism spectrum disorder: A systematic review. Gut Pathog. 2021, 13, 54. [CrossRef] [PubMed]

50. Olovo, C.V.; Huang, X.; Zheng, X.; Xu, M. Faecal microbial biomarkers in early diagnosis of colorectal cancer. J. Cell. Mol. Med. 2021, 25, 10783-10797. [CrossRef]

51. Zhou, J.; Sun, S.; Luan, S.; Xiao, X.; Yang, Y.; Mao, C.; Chen, L.; Zeng, X.; Zhang, Y.; Yuan, Y. Gut Microbiota for Esophageal Cancer: Role in Carcinogenesis and Clinical Implications. Front. Oncol. 2021, 11, 4196. [CrossRef]

52. Microbiota Transplant in Advanced Lung Cancer Treated with Immunotherapy. Available online: Clinicaltrials.org (accessed on 16 November 2021). 